\title{
Thermal Stability and Rheological Behaviors of High-Density Polyethylene/Fullerene Nanocomposites
}

\author{
Liping Zhao,, ${ }^{1,2}$ Ping'an Song, ${ }^{3}$ Zhenhu Cao, ${ }^{1,2}$ Zhengping Fang, ${ }^{1,2}$ \\ and Zhenghong Guo' \\ ${ }^{1}$ Laboratory of Polymer Materials and Engineering, Ningbo Institute of Technology, Zhejiang University, Ningbo 315100, China \\ ${ }^{2}$ MOE Key Laboratory of Macromolecular Synthesis and Functionalization, Zhejiang University, Hangzhou 310027, China \\ ${ }^{3}$ Department of Materials, College of Engineering, Zhejiang Agriculture \& Forest University, Hangzhou 300311, China
}

Correspondence should be addressed to Zhenghong Guo, guozhenghong@nit.zju.edu.cn

Received 3 June 2011; Accepted 20 October 2011

Academic Editor: Steve Acquah

Copyright (c) 2012 Liping Zhao et al. This is an open access article distributed under the Creative Commons Attribution License, which permits unrestricted use, distribution, and reproduction in any medium, provided the original work is properly cited.

\begin{abstract}
High-density polyethylene/fullerene (HDPE/ $\mathrm{C}_{60}$ ) nanocomposites with the $\mathrm{C}_{60}$ loading that varied from 0.5 to $5.0 \%$ by weight were prepared via melt compounding. Thermogravimetric analysis (TGA) and differential scanning calorimetry (DSC) results showed that the presence of $\mathrm{C}_{60}$ could remarkably enhance the thermal properties of HDPE. A very low $\mathrm{C}_{60}$ loading $(0.5 \mathrm{wt} \%)$ increased the onset degradation temperature from $389^{\circ} \mathrm{C}$ to $459^{\circ} \mathrm{C}$ and decreased the heat release from $3176 \mathrm{~J} / \mathrm{g}$ to $1490 \mathrm{~J} / \mathrm{g}$. The larger the loading level of $\mathrm{C}_{60}$, the better the thermal stability of $\mathrm{HDPE} / \mathrm{C}_{60}$ nanocomposites. Rheological investigation results showed that the free radical trapping effect of $\mathrm{C}_{60}$ was responsible for the improved thermal stability of HDPE.
\end{abstract}

\section{Introduction}

Soon after the discovery of buckminsterfullerene, $\mathrm{C}_{60}$, it was able to be produced in bulk quantities, which inspired scientists worldwide to explore its fascinating chemistry, and it has now become the most intensely researched single molecule in modern science [1-3]. A significant aspect of the $\mathrm{C}_{60}$ chemistry is its high reactivity towards free radicals, and $\mathrm{C}_{60}$ has 30 carbon-carbon double bonds which can trap more than 34 free radicals; thus it is known as a radical sponge [4]. The free radical reaction of $\mathrm{C}_{60}$ with various compounds has been extensively studied [4-7].

Since the thermal degradation of polymers is a free radical chain reaction, the presence of $\mathrm{C}_{60}$ in polymer may trap the free radicals produced during the degradation process. These suggest the possible use of fullerene as an effective radical scavenger in chain reactions during thermal degradation. It has been reported that $2 \mathrm{wt} \%$ fullerene $\left(\mathrm{C}_{60}\right)$ could increase the onset degradation temperature $\left(T_{\text {onset }}\right)$ and the maximum degradation temperature $\left(T_{\max }\right)$ of $\mathrm{PP}$ by 20 and $62^{\circ} \mathrm{C}$, respectively $[8,9]$. The presence of $C_{60}$ could delay the thermal oxidation and improve the thermal stability of $\mathrm{PP}$, which could be attributed to the high reactivity of $\mathrm{C}_{60}$ towards free radicals.

The present paper mainly focused on studying the influence of $\mathrm{C}_{60}$ on the thermal degradation behavior and rheological properties of high-density polyethylene. Concerning that the thermal degradation of polyethylene is done also via a free radical chain scission process as $\mathrm{PP}, \mathrm{C}_{60}$ is expected to have positive effect on improving the thermal stability of PE.

\section{Materials and Methods}

2.1. Materials. High-density Polyethylene (HDPE, 5000 S, $\mathrm{MFR}=0.9 \mathrm{~g} / 10 \mathrm{~min}$ ) was purchased from Yangzi Petrochemical Co., Ltd, and $\mathrm{C}_{60}$ (purity: >99\%) was bought from Henan Puyang Co., Ltd.

2.2. Preparation of HDPE/C 60 Nanocomposites. HDPE/ $\mathrm{C}_{60}$ nanocomposites were prepared via melt compounding at $180^{\circ} \mathrm{C}$ in a ThermoHaake rheomixer with a rotor speed of $60 \mathrm{rpm}$ for $8 \mathrm{~min}$. Nanocomposites containing $0.5 \mathrm{wt} \%$, $1.0 \mathrm{wt} \%, 2.5 \mathrm{wt} \%$, and $5.0 \mathrm{wt} \% \mathrm{C}_{60}$ were designated as $\mathrm{C}_{60}$ $0.5 \%, \mathrm{C}_{60}-1.0 \%, \mathrm{C}_{60}-2.5 \%$, and $\mathrm{C}_{60}-5.0 \%$. 


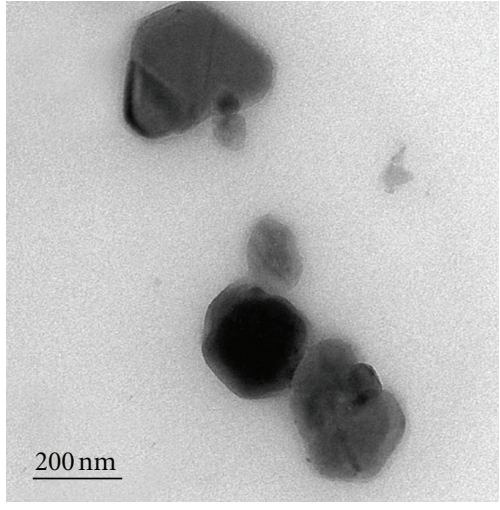

(a)

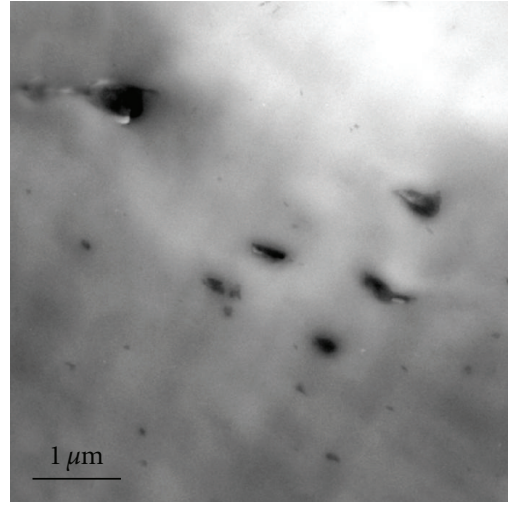

(b)

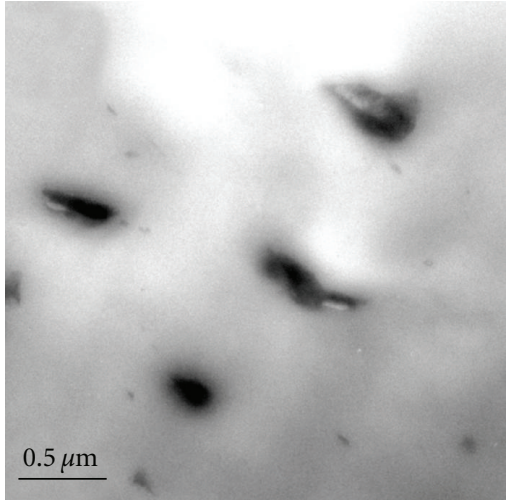

(c)

FIGURE 1: TEM microphotographs for pristine $\mathrm{C}_{60}$ (a) and $\mathrm{C}_{60}-5.0 \%$ (b) and (c).

2.3. Measurements and Characterization. Thermogravimetric analysis (TGA) was performed on a STA 409 PC thermal analyzer at heating rate of $20^{\circ} \mathrm{C} / \mathrm{min}$ in air atmosphere and $\mathrm{N}_{2}$ atmosphere, with a scanning range from 30 to $700^{\circ} \mathrm{C}$, and each specimen was examined in triplicate.

The rheological properties of HDPE and its nanocomposites were conducted on a controlled strain rheometer (Haake MARS) in air environment. The samples were pressed at $180^{\circ} \mathrm{C}$ under $15 \mathrm{MPa}$ to get the disklike specimens with $25 \mathrm{~mm}$ in diameter and $1.2 \mathrm{~mm}$ in thickness. The isothermal dynamic frequency sweeps were performed under the condition of the frequency range, strain amplitude, and temperature being $100-0.01 \mathrm{rads}^{-1}$ with the strain of $1 \%$ at $180^{\circ} \mathrm{C}$ and $300^{\circ} \mathrm{C}$, respectively. Temperature scanning test was performed in the range from 180 to $300^{\circ} \mathrm{C}$ with the $1 \%$ strain and a fixed frequency at $1 \mathrm{rads}^{-1}$.

The dispersion of $\mathrm{C}_{60}$ in the HDPE matrix was observed by transmission electron microscopy (TEM, JEM-1200EX).

\section{Results and Discussion}

3.1. Dispersion of $C_{60}$ in HDPE Matrix. The diameter of the spherical $\mathrm{C}_{60}$ molecule is $0.71 \mathrm{~nm}$, and its crystal size differs with different methods of fabrication [9]. Figure 1 shows the TEM images for pure $\mathrm{C}_{60}$ and $\mathrm{C}_{60}-5 \%$. The size of $\mathrm{C}_{60}$ crystals used in this work from Figure $1(\mathrm{a})$ is from 70 to $200 \mathrm{~nm}$. From Figure 1(c), it is shown that many of $\mathrm{C}_{60}$ crystallites in the HDPE matrix were shaped in ellipsoidal, rodlike. This phenomenon may be caused by the strong shear force during blending. The shear force could destroy the primary stack of $\mathrm{C}_{60}$ crystallites and these crystallites rearrange to different type. In the HDPE matrix, $\mathrm{C}_{60}$ crystallites aggregates and does not disperse well through melt blending, as observed from Figure 1(b). The size of some $\mathrm{C}_{60}$ domains in nanocomposites is about $500 \mathrm{~nm}$ or even large.

3.2. Thermal Properties of HDPE/C 60 Nanocomposites. The thermal stability of HDPE and HDPE/C 60 nanocomposites was tested by TGA, and their TG and DTG curves in nitrogen
Table 1: Detailed data obtained from TGA tests for HDPE and HDPE/ $\mathrm{C}_{60}$ nanocomposites in nitrogen.

\begin{tabular}{lcc}
\hline Sample & $T_{\text {onset }}\left({ }^{\circ} \mathrm{C}\right)$ & $T_{\max }\left({ }^{\circ} \mathrm{C}\right)$ \\
\hline HDPE & 389 & 483 \\
$\mathrm{C}_{60}-0.5 \%$ & 459 & 497 \\
$\mathrm{C}_{60}-1.0 \%$ & 460 & 496 \\
$\mathrm{C}_{60}-2.5 \%$ & 462 & 496 \\
$\mathrm{C}_{60}-5.0 \%$ & 463 & 495 \\
\hline
\end{tabular}

atmosphere are shown in Figure 2, with detailed data listed in Table 1. At the initial stage of degradation (before $400^{\circ} \mathrm{C}$ ), $\mathrm{C}_{60}$ reacts easily with low-molecular-weight alkyl radicals with formation of remarkable persistent products $\mathrm{RnC}_{60}$ (where $n=1,2,3 \ldots$ ) $[10,11]$, which caused that the decomposition of $\mathrm{HDPE} / \mathrm{C}_{60}$ nanocomposites is slower than pure HDPE. The onset thermal decomposition temperature ( $\left.T_{\text {onset }}\right)$ of HDPE is noticeably increased with the addition of $\mathrm{C}_{60}$. For example, the $T_{\text {onset }}$ of $\mathrm{C}_{60}-0.5 \%$ is $459^{\circ} \mathrm{C}$, about $70^{\circ} \mathrm{C}$ higher than pure HDPE. With increasing $\mathrm{C}_{60}$ content, the onset temperature of $\mathrm{HDPE} / \mathrm{C}_{60}$ nanocomposites changes slightly. From DTG curves, the maximum decomposition temperature $\left(T_{\max }\right)$ is obtained, with $T_{\max } 497^{\circ} \mathrm{C}$ for $\mathrm{C}_{60^{-}}$ $0.5 \%$, about $14^{\circ} \mathrm{C}$ higher than pure HDPE.

Figures 3 and 4 present the TG and DSC curves for HDPE and its composites in air atmosphere, with detailed data given in Table 2. In air atmosphere, the presence of oxygen could enhance the thermal oxidation decomposition of HDPE nanocomposites remarkably. HDPE experiences a rapid thermal oxidation decomposition accompanied by hydrogen abstraction [12]. The ( $\left.T_{\text {onset }}\right)$ of HDPE is about $323^{\circ} \mathrm{C}$, and two-step decomposition processes are observed at around $398^{\circ} \mathrm{C}$ and $456^{\circ} \mathrm{C}$ (see Table 2). The first step decomposition is the oxidation of HDPE [13]. The second step may be the decomposition of oxidation products formed by the oxidation of HDPE. $\mathrm{C}_{60}$, as the radical sponge, could capture the free radicals produced during the degradation process. Obviously, the presence of $\mathrm{C}_{60}$ delays the oxidation degradation of parent polymer and the first-step $T_{\max }$ disappears, and the $T_{\text {onset }}$ of the nanocomposites noticeably 
TABLE 2: Detailed data obtained from TGA and DSC tests for HDPE and HDPE/ 60 nanocomposites in air.

\begin{tabular}{lcccc}
\hline Sample & & Data from TGA & & $T_{\max }$ \\
& $T_{\text {onset }}\left({ }^{\circ} \mathrm{C}\right)$ & Stage 1 & Stage 2 & Data from DSC $\Delta \mathrm{H}_{d}(\mathrm{~J} / \mathrm{g})$ \\
\hline $\mathrm{HDPE}$ & 323 & 398 & 456 & 3176 \\
$\mathrm{C}_{60}-0.5 \%$ & 361 & - & 451 & 1490 \\
$\mathrm{C}_{60}-1.0 \%$ & 387 & - & 444 & 1521 \\
$\mathrm{C}_{60}-2.5 \%$ & 431 & - & 461 & 842 \\
$\mathrm{C}_{60}-5.0 \%$ & 416 & - & 448 & 1892 \\
\hline
\end{tabular}

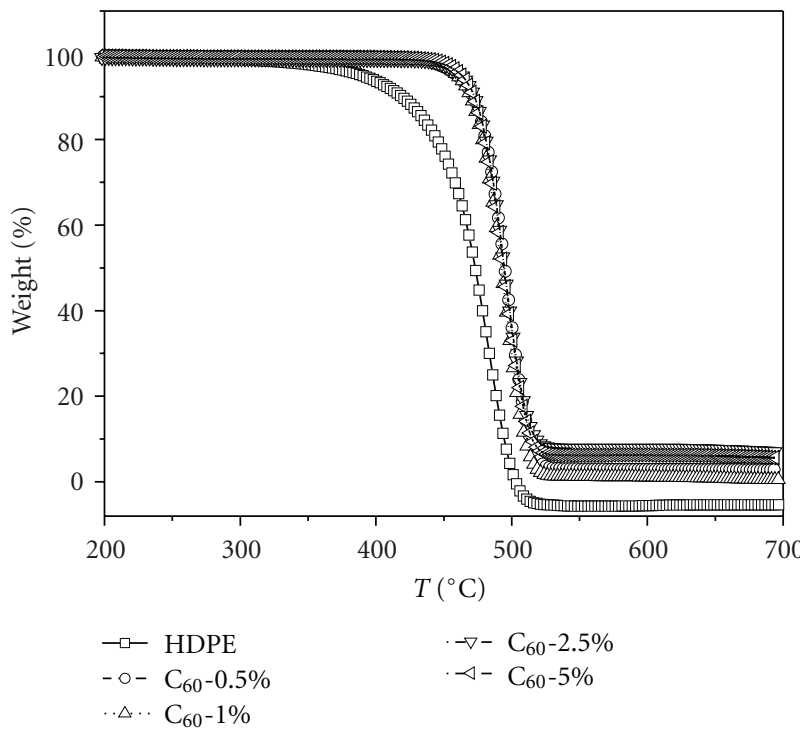

(a)

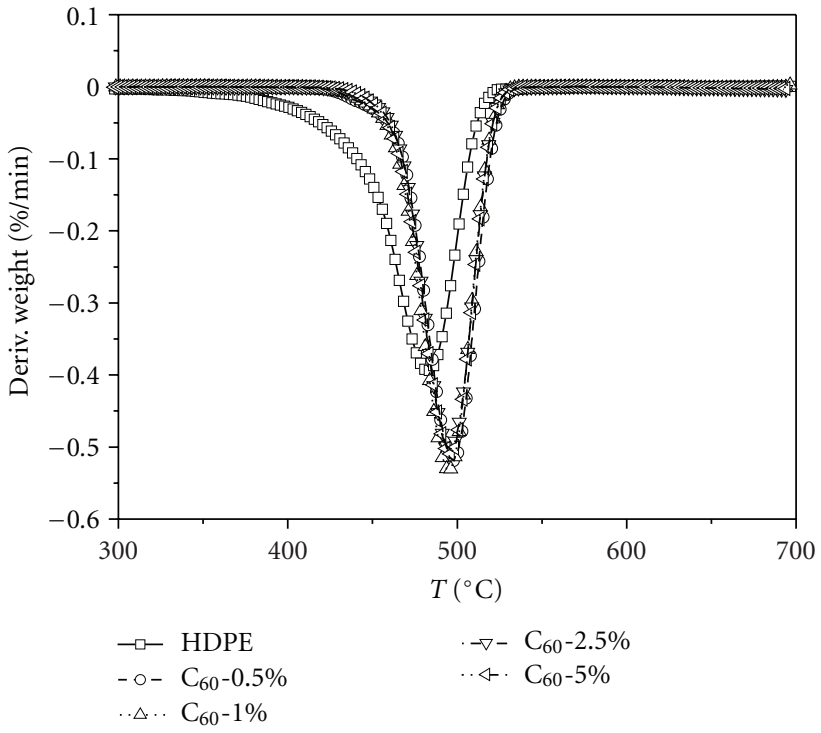

(b)

Figure 2: TG (a) and DTG (b) curves for pristine HDPE and HDPE/ $\mathrm{C}_{60}$ nanocomposites in nitrogen.

increase with the increase of $\mathrm{C}_{60}$ content. As for $\mathrm{C}_{60}-2.5 \%$, its $T_{\text {onset }}$ is around $431^{\circ} \mathrm{C}, 108^{\circ} \mathrm{C}$ higher than pure HDPE, which indicates that the presence of $\mathrm{C}_{60}$ slows down the thermal oxidation decomposition of HDPE remarkably. However, when the contents of $\mathrm{C}_{60}$ in the matrix exceed $2.5 \mathrm{wt} \%$, the $T_{\text {onset }}$ of the nanocomposites decreases with the content of $\mathrm{C}_{60}$. At high loading (as for $\mathrm{C}_{60}-5.0 \%$ ), $\mathrm{C}_{60}$ may tend to attract each other, which causes the agglomeration (as shown in Figure 1) instead of trapping the alkyl fragments radicals bringing down the thermal stability of HDPE/ $\mathrm{C}_{60}$ nanocomposites.

The difference in thermal behavior between air and nitrogen atmospheres indicates that the presence of oxygen could speed up the thermal oxidation decomposition of HDPE nanocomposites remarkably. The oxygen and alkyl fragment radicals trapped by $\mathrm{C}_{60}$ in nanocomposites during the thermal decomposition are competitive.

DSC measurements could provide the heat enthalpy of thermal degradation during the decomposition process of materials. Figure 4 presents the DSC curves of HDPE/ $\mathrm{C}_{60}$ nanocomposites in air atmosphere. In air atmosphere, HDPE/ $\mathrm{C}_{60}$ nanocomposites experiences rapid exothermal oxidation decomposition at high temperature. The enthalpy
$\left(\Delta \mathrm{H}_{d}\right)$ is an important parameter since it could quantify the heat evolution produce in the process of oxidation decomposition. The enthalpies of the nanocomposites are greatly reduced from $3176 \mathrm{~J} / \mathrm{g}$ for HDPE to $1490 \mathrm{~J} / \mathrm{g}$ for $\mathrm{C}_{60}-0.5 \%$, indicating that the nanocomposites release much less heat in the process of oxidation dehydrogenization and this phenomenon is favorable to flame retarded polymer materials.

3.3. Mechanism for the Thermal Stability of HDPE/ $C_{60}$ Nanocomposites. In order to clarify the mechanism for $\mathrm{C}_{60}$ improving the thermal stability of HDPE, the rheological measurements were introduced to investigate the viscoelastic behaviors of the nanocomposites. For investigating the viscoelastic behavior of the nanocomposites in the heating process, temperature scanning measurements were performed. Figure 5 presents the curves of temperature dependence of complex viscosity $\left(\eta^{*}\right)$ for HDPE and its nanocomposites. Clearly, with the increase of temperature, the complex viscosity $\left(\eta^{*}\right)$ of nanocomposites decreases, and then increases sharply. The critical temperature is defined as $T_{\mathrm{c}}$, at which $\eta^{*}$ starts to increase or crosslink reaction occurs. The easier movement of polymer chains during heating, or 


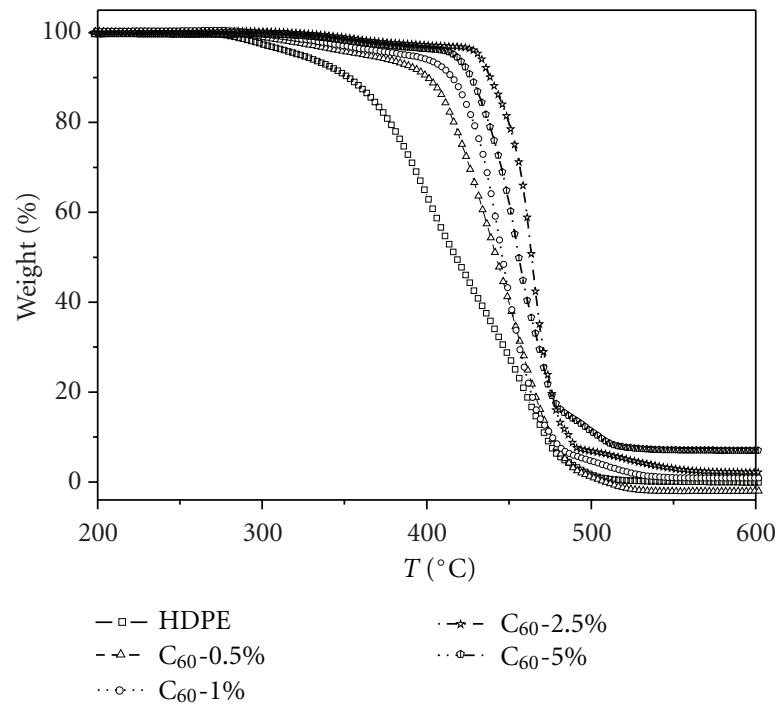

(a)

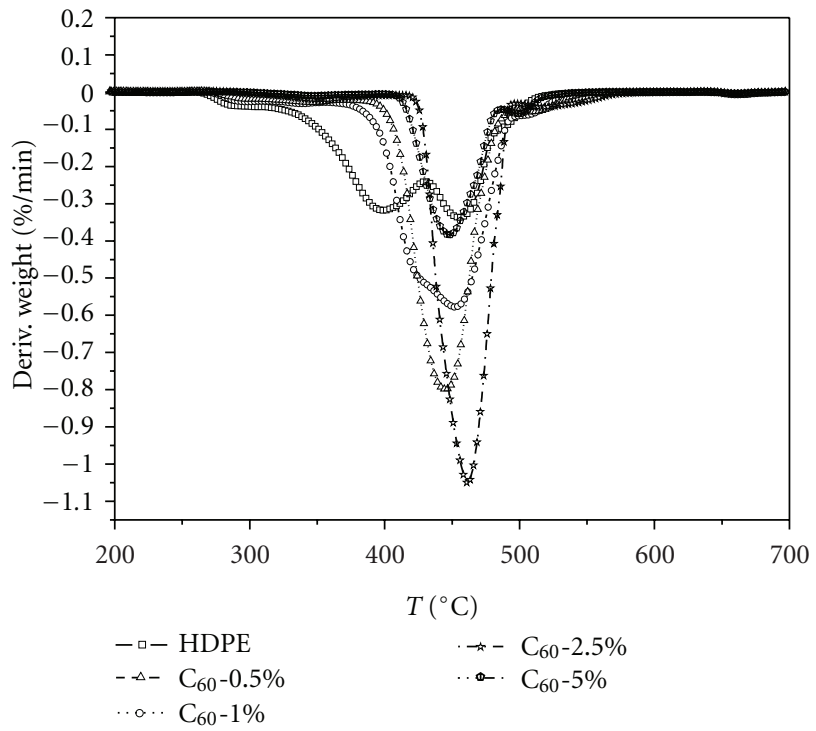

(b)

FIgURe 3: TG (a) and DTG (b) curves for pristine HDPE and nanocomposites in air.

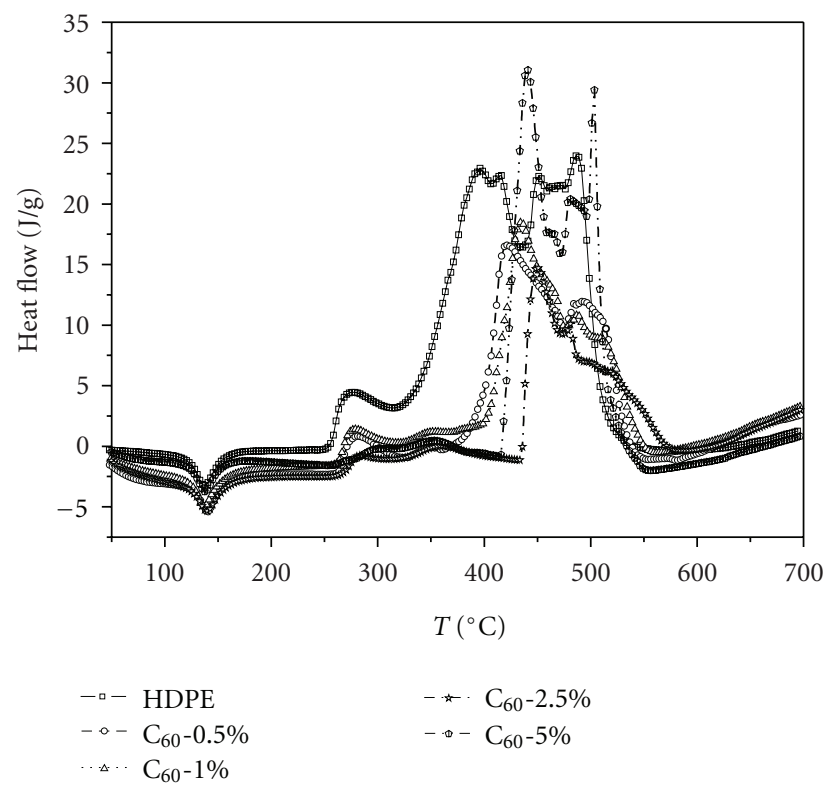

Figure 4: DSC curves for HDPE and HDPE/C 60 nanocomposites.

the occurrence of degradation of polymer can cause the decrease of $\eta^{*}$. The increase of $\eta^{*}$ is due to the occurrence of an oxidation crosslink or the oxidation crosslink reaction overwhelming the polymer decomposition. In the case of pure HDPE, it gives a $T_{c}$ of $285^{\circ} \mathrm{C}$. For HDPE/ $\mathrm{C}_{60}$ nanocomposites, their $T_{\mathrm{c}}$ is about $45^{\circ} \mathrm{C}$ lower than that of HDPE, implying that another kind of crosslink reaction occurred in the process of heating for HDPE/ $\mathrm{C}_{60}$ systems, which speeds up the crosslink reaction whether before or after oxidation crosslinking takes place.

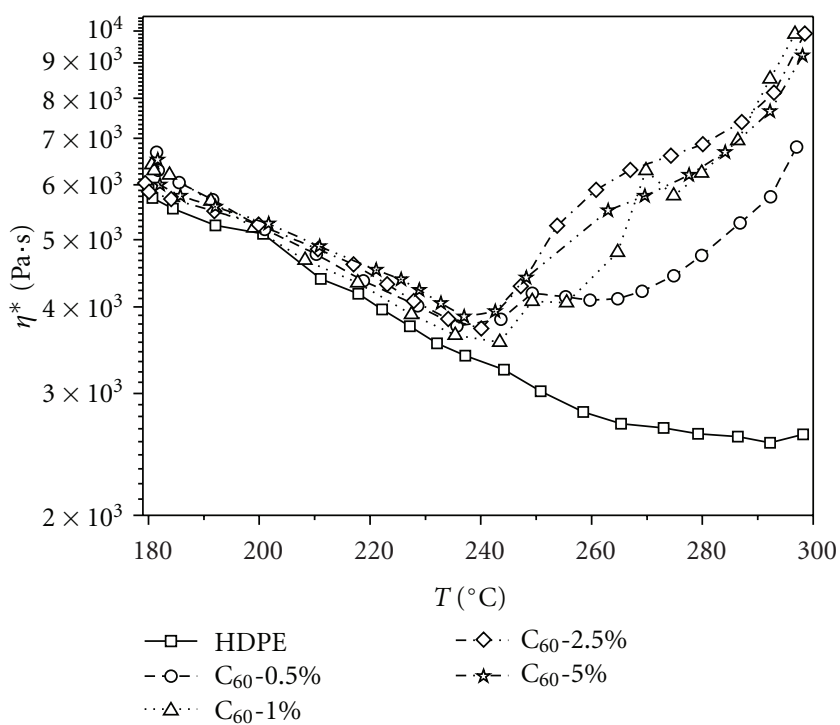

FIGURE 5: Dependence of complex viscosity $\left(\eta^{*}\right)$ on temperature for $\mathrm{HDPE}$ and $\mathrm{HDPE} / \mathrm{C}_{60}$ nanocomposites.

The viscoelastic behaviors of the nanocomposites at $180^{\circ} \mathrm{C}$ were studied and those of parent polymer, HDPE, were also used as a comparison. Figures 6 and 7 show the storage moduli $\left(G^{\prime}\right)$ and complex viscosity $\left(\eta^{*}\right)$ as a function of frequency $(\omega)$ of HDPE and its nanocomposites. Some researchers have found that both $G^{\prime}$ and $\eta^{*}$ have much larger values than those of parent polymers in the low $\omega$ regime for the nanocomposites containing CNTs [14-17] or clay $[18,19]$, suggesting that the presence of CNTs or clay affects the relaxation and motion of polymer chains due to their spatial geometry. Most authors attribute these viscoelastic behaviors to the formation of CNT or clay networks in the 


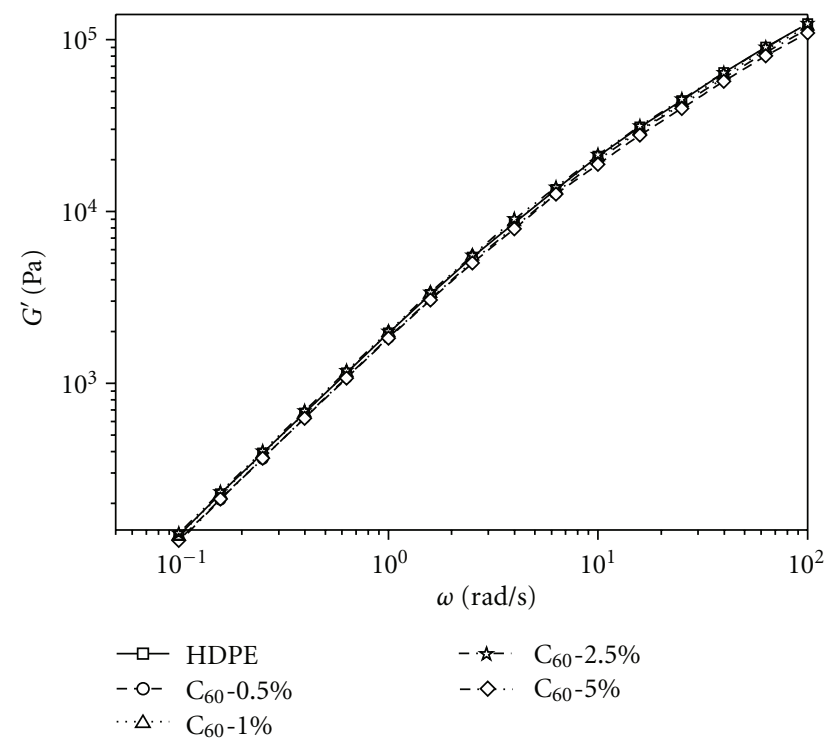

Figure 6: Plots of storage moduli $\left(G^{\prime}\right)$ versus shifted frequency for consecutive small amplitude oscillatory shear sweeps performed at $180^{\circ} \mathrm{C}$.

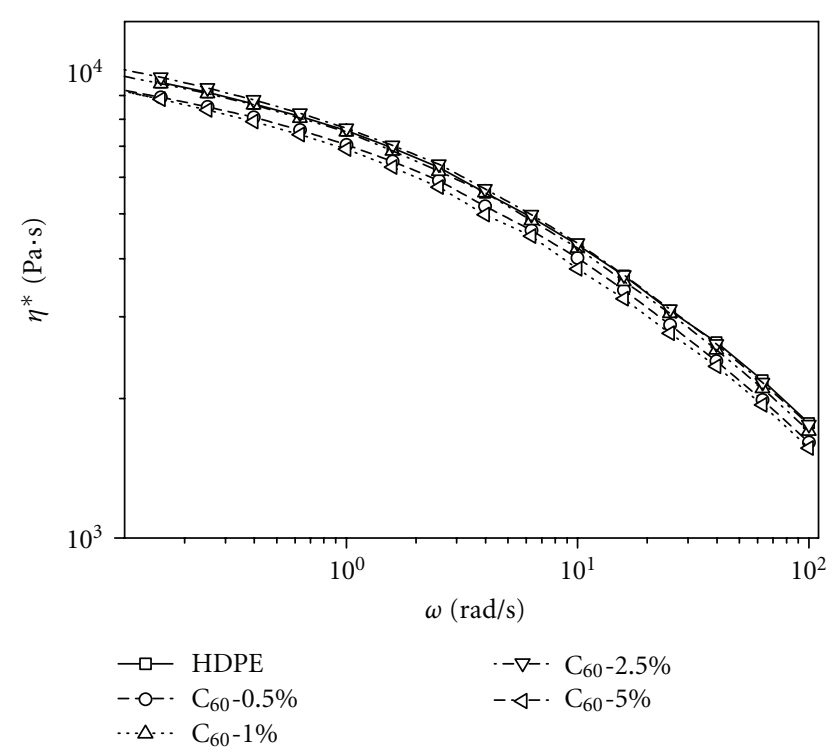

FIGURe 7: Plots of complex viscosity versus shifted frequency for consecutive small amplitude oscillatory shear sweeps performed at $180^{\circ} \mathrm{C}$.

polymer matrix. However, in the high $\omega$ region, the addition of CNTs and clay does not significantly affect the $G^{\prime}$ or $\eta^{*}$ of polymers. Unlike CNTs and clay, whether in the low $\omega$ region or high $\omega$ region, not much obvious difference in $G^{\prime}$ and $\eta^{*}$ is observed for the HDPE/ $\mathrm{C}_{60}$ nanocomposites with various $\mathrm{C}_{60}$ contents. The oxidation degradation of HDPE does not occur at $180^{\circ} \mathrm{C}$ (as shown in Figure 3 and Table 2). And not enough free radicals react with $\mathrm{C}_{60}$. Therefore, the incorporation of $\mathrm{C}_{60}$ does not affect the movement and relaxation of polymer chain segments remarkably.

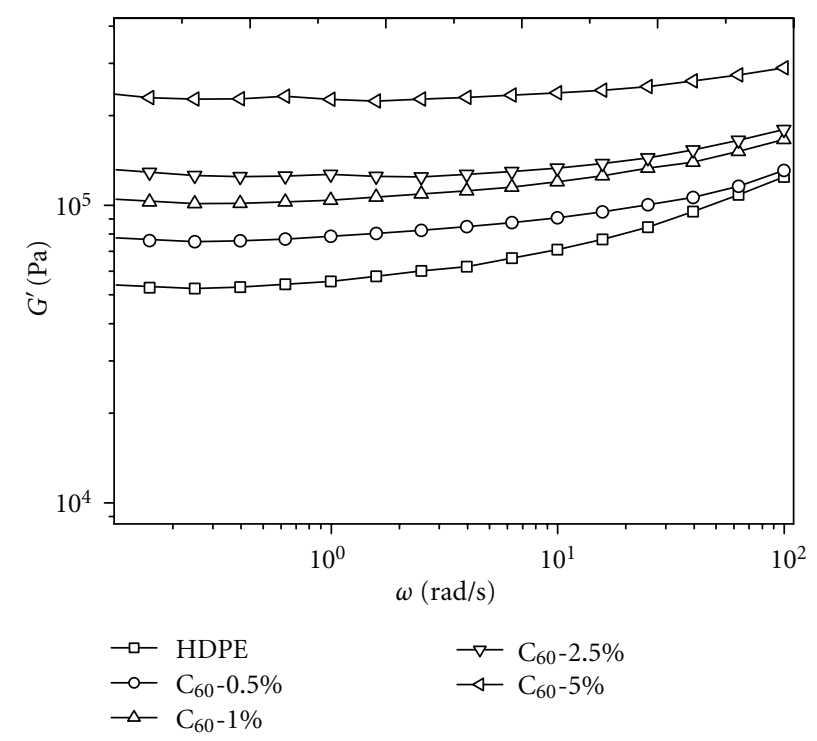

Figure 8: Plots of storage modulus versus shifted frequency for consecutive small amplitude oscillatory shear sweeps performed at $300^{\circ} \mathrm{C}$.

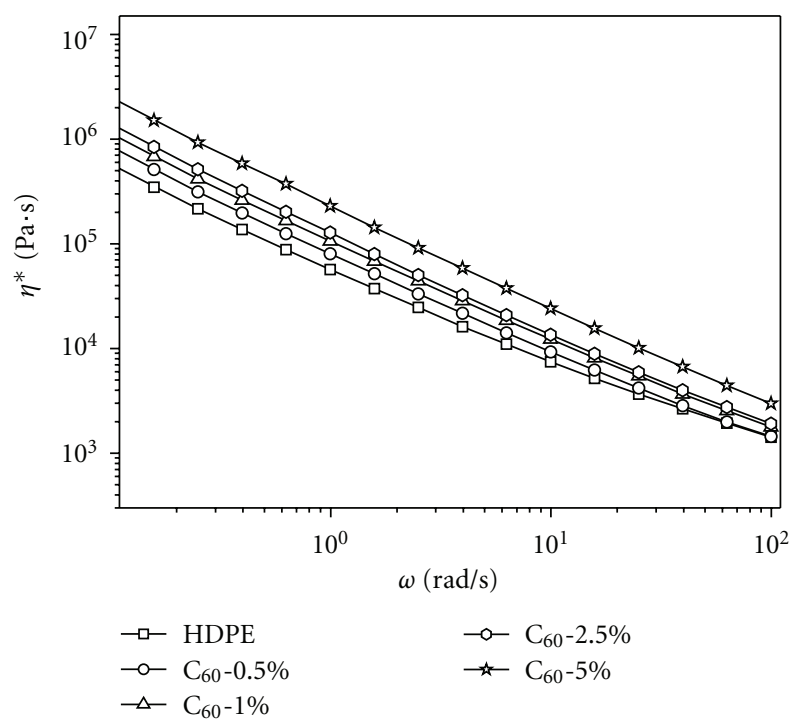

Figure 9: Plots of complex viscosity versus shifted frequency for consecutive small amplitude oscillatory shear sweeps performed at $300^{\circ} \mathrm{C}$.

The viscoelastic behaviors of the nanocomposites at $300^{\circ} \mathrm{C}$ after dynamic temperature scanning measurements were also studied. Figures 8 and 9 show the storage moduli $\left(G^{\prime}\right)$ and complex viscosity $\left(\eta^{*}\right)$ as a function of frequency $(\omega)$ of HDPE and its nanocomposites at $300^{\circ} \mathrm{C}$. The increase of complex viscosity with $\mathrm{C}_{60}$ content is concomitant with the increase of the storage moduli. The storage moduli for the nanocomposites show a monotonic increase at all frequencies with increasing $\mathrm{C}_{60}$ content. The $G^{\prime}$ versus frequency curve for the nanocomposites appears to be approaching a plateau at low frequencies. It has been proposed that this "plateau" effect is derived from interconnected structures of 
isometric fillers that result in an apparent yield stress which is manifest by a plateau in either $G^{\prime}$ or $\eta^{*}$ versus frequency plots $[20,21]$. Exposed at $300^{\circ} \mathrm{C}$ for a long time, many alkyl radicals appear, coupled with the interfacial interactions between free radicals and $\mathrm{C}_{60}$. The restraint for the move and relaxation of polymer chains increased $G^{\prime}$ and $\eta^{*}$, which is the evidence for the presence of a chemical reaction between the HDPE matrix and $\mathrm{C}_{60}$.

\section{Conclusion}

The presence of $\mathrm{C}_{60}$ could enhance the thermal stability of HDPE. A very low $\mathrm{C}_{60}$ loading $(0.5 \mathrm{wt} \%)$ increases the $T_{\text {onset }}$ from $389^{\circ} \mathrm{C}$ to $459^{\circ} \mathrm{C}$ and decreases the heat release from $3176 \mathrm{~J} / \mathrm{g}$ to $1490 \mathrm{~J} / \mathrm{g}$. The free radical trapping effect of $\mathrm{C}_{60}$ is responsible for the improved thermal stability of HDPE. Thus, $\mathrm{C}_{60}$ is expected to be an efficient thermal stabilizer to the polymer materials that degraded with a free radical chain scission process.

\section{Acknowledgment}

This work was financially supported by the National Natural Science Foundation of China (no. 51073140).

\section{References}

[1] D. E. H. Jones, “The academic sphere," Nature, vol. 381, no. 6581, pp. 381-384, 1996.

[2] R. Taylor and D. R. M. Walton, "The chemistry of fullerenes," Nature, vol. 363, no. 24, pp. 685-693, 1993.

[3] F. Diederich and C. Thilgen, "Covalent fullerene chemistry," Science, vol. 271, no. 5247, pp. 317-323, 1996.

[4] P. J. Krusic, E. Wasserman, P. N. Keizer, J. R. Morton, and K. F. Preston, "Radical reactions of $\mathrm{C}_{60}$," Science, vol. 254, no. 5035, pp. 1183-1185, 1991.

[5] L. B. Gan, S. H. Huang, X. Zhang et al., "Fullerenes as a tert-butylperoxy radical trap, metal catalyzed reaction of tert-butyl hydroperoxide with fullerenes, and formation of the first fullerene mixed peroxides $\mathrm{C}_{60}(\mathrm{O})\left(\mathrm{OO}^{t} \mathrm{BU}\right) 4$ and $\mathrm{C}_{70}\left(\mathrm{OO}^{t} \mathrm{BU}\right)_{10}$," Journal of the American Chemical Society, vol. 124, no. 45, pp. 13384-13385, 2002.

[6] B. Z. Tang, S. M. Leung, H. Peng, N. T. Yu, and K. C. Su, "Direct fullerenation of polycarbonate via simple polymer reactions," Macromolecules, vol. 30, no. 10, pp. 2848-2852, 1997.

[7] T. Cao and S. E. Webber, "Free radical copolymerization of styrene and $\mathrm{C}_{60}$," Macromolecules, vol. 29, no. 11, pp. 38263830, 1996.

[8] Z. P. Fang, P. A. Song, L. F. Tong, and Z. H. Guo, "Thermal degradation and flame retardancy of polypropylene/ $\mathrm{C}_{60}$ nanocomposites," Thermochimica Acta, vol. 473, no. 1-2, pp. 106-108, 2008.

[9] P. A. Song, Z. P. Fang, Y. Zhu, and L. Tong, " $\mathrm{C}_{60}$ reduces the flammability of polypropylene nanocomposites by in situ forming a gelled-ball network," Nanotechnology, vol. 19, no. 22, Article ID 225707, 2008.

[10] P. J. Krusic, E. Wasserman, B. A. Parkinson et al., "Electron spin resonance study of the radical reactivity of $\mathrm{C}_{60}$," Journal of the American Chemical Society, vol. 113, no. 16, pp. 6274$6275,1991$.
[11] J. R. Morton, K. F. Preston, P. J. Krusic, S. A. Hill, and E. Wasserman, "The dimerization of $\mathrm{RC}_{60}$ radicals," Journal of the American Chemical Society, vol. 114, no. 13, pp. 5454-5455, 1992.

[12] M. Zanetti, G. Camino, P. Reichert, and R. Mulhaupt, "Thermal behaviour of poly(propylene) layered silicate nanocomposites," Macromolecular Rapid Communications, vol. 22, no. 3, pp. 176-180, 2001.

[13] G. Wu, Y. Song, Q. Zheng, M. Du, and P. Zhang, "Dynamic rheological properties for HDPE/CB composite melts," Journal of Applied Polymer Science, vol. 88, no. 9, pp. 2160-2167, 2003.

[14] T. Kashiwagi, E. Grulke, J. Hilding, R. Harris, W. Awad, and J. Douglas, "Thermal degradation and flammability properties of poly(propylene)/carbon nanotube composites," Macromolecular Rapid Communications, vol. 23, no. 13, pp. 761-765, 2002.

[15] T. Kashiwagi, F. Du, K. I. Winey et al., "Flammability properties of polymer nanocomposites with single-walled carbon nanotubes: effects of nanotube dispersion and concentration," Polymer, vol. 46, no. 2, pp. 471-481, 2005.

[16] T. Kashiwagi, F. Du, J. F. Douglas, K. I. Winey, R. H. Harris, and J. R. Shields, "Nanoparticle networks reduce the flammability of polymer nanocomposites," Nature Materials, vol. 4, no. 12, pp. 928-933, 2005.

[17] S. B. Kharchenko, J. F. Douglas, J. Obrzut, E. A. Grulke, and K. B. Migler, "Flow-induced properties of nanotube-filled polymer materials," Nature Materials, vol. 3, no. 8, pp. 564$568,2004$.

[18] M. A. Treece and J. P. Oberhauser, "Soft glassy dynamics in polypropylene-clay nanocomposites," Macromolecules, vol. 40, no. 3, pp. 571-582, 2007.

[19] C. O. Rohlmann, M. D. Failla, and L. M. Quinzani, "Linear viscoelasticity and structure of polypropylene-montmorillonite nanocomposites," Polymer, vol. 47, no. 22, pp. 7795-7804, 2006.

[20] P. Potschke, M. Abdel-Goad, I. Alig, S. Dudkin, and D. Lellinger, "Rheological and dielectrical characterization of melt mixed polycarbonate-multiwalled carbon nanotube composites," Polymer, vol. 45, no. 26, pp. 8863-8870, 2004.

[21] L. A. Utracki, "Flow and flow orientation of composites containing anisometric particles," Polymer Composites, vol. 7, no. 5, pp. 274-282, 1986. 

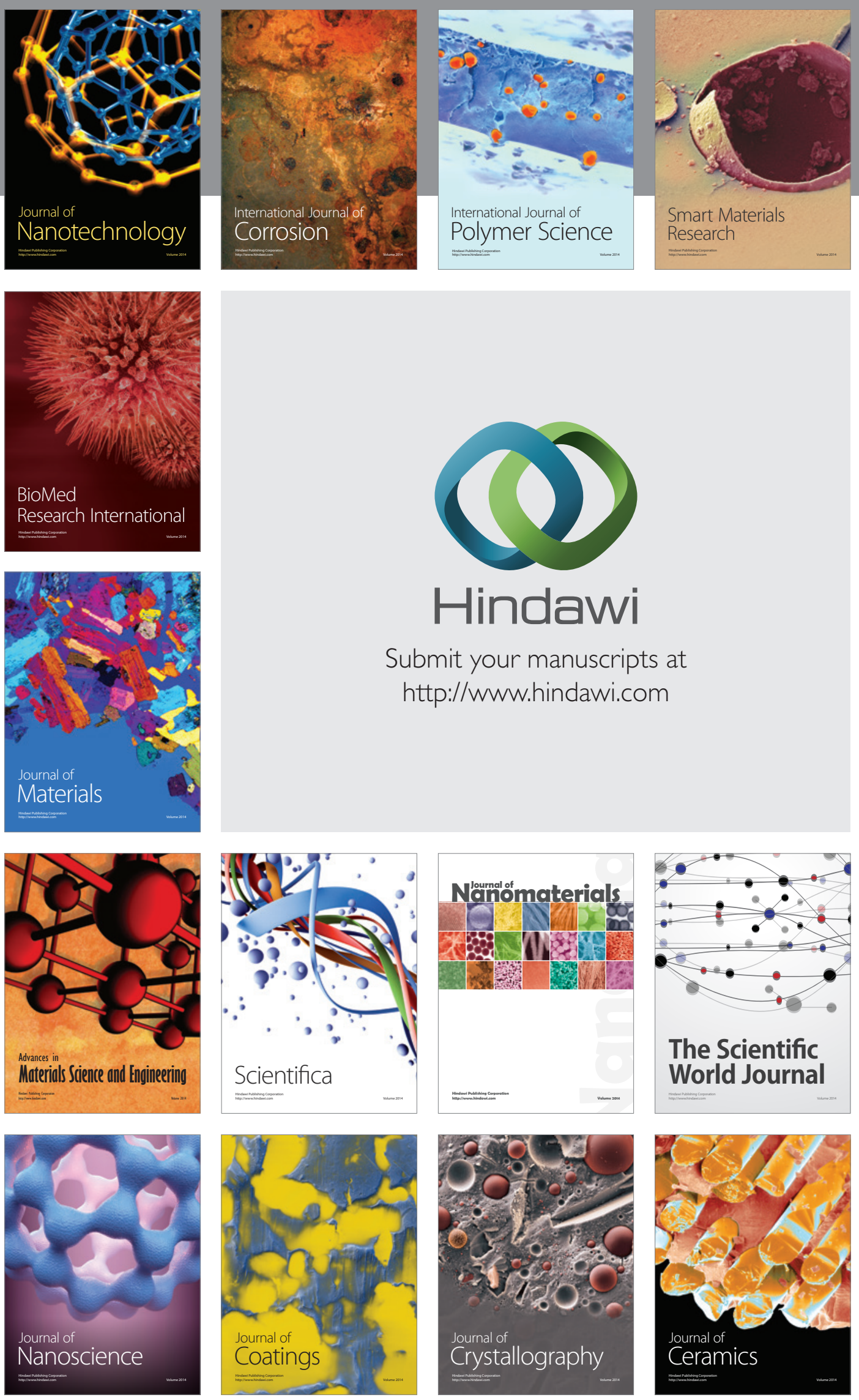

The Scientific World Journal

Submit your manuscripts at

http://www.hindawi.com

\section{World Journal}

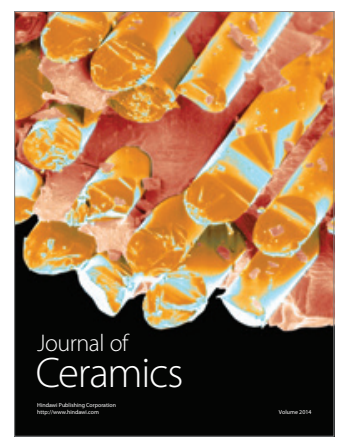

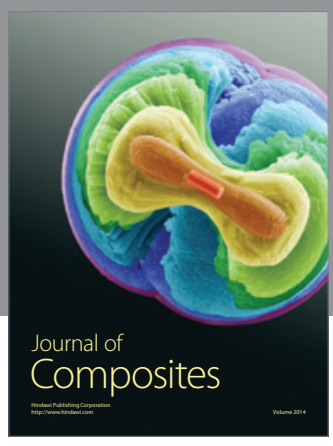
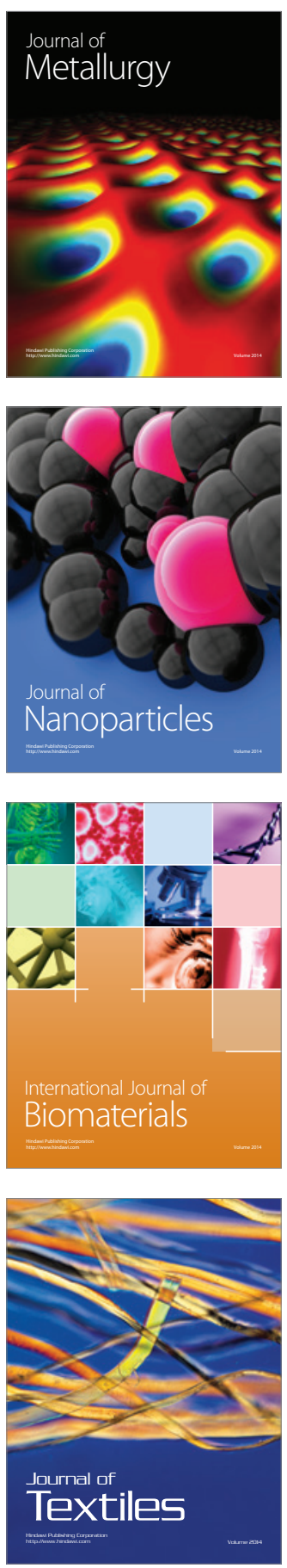